\title{
THE USE OF PLASMAPHERESIS IN TREATMENT OF PATIENTS WITH INFERTILITY, PERITONEAL ENDOMETRIOSIS AND NAT2 GENE POLYMORPHISM
}

\author{
Ekaterina Dubinskaya \\ Medicine department \\ People's Friendship University of Russia, Moscow, Russian Federation \\ 6 Miklouho-Maclay str., Moscow, Russia, 117198 \\ eka-dubinskaya@yandex.ru \\ Natalia Lapteva \\ Obstetrics, Gynecology and Reproductive Medicine department \\ People's Friendship University of Russia, Moscow, Russian Federation \\ 6 Miklouho-Maclay str., Moscow, Russia, 117198 \\ nvlapteva@gmail.com \\ Yana Lukyanova \\ Obstetrics, Gynecology and Reproductive Medicine department \\ People's Friendship University of Russia, Moscow, Russian Federation \\ 6 Miklouho-Maclay str., Moscow, Russia, 117198 \\ nvlapteva@gmail.com
}

\begin{abstract}
It is known that 30-40\% of patients with peritoneal endometriosis suffer from infertility. Half of the patients with endometriosis are identified point mutation in NAT2 - gene, which plays an important role in the acetylation of aromatic and heterocyclic amines, in the accumulation of endotoxins, activation of free radical oxidation, impaired microcirculation. These factors involve the use of methods of gemapheresis which have detoxification, the blood rheology corrective and immune corrective effects.

The purpose of this study was to evaluate the efficacy of therapeutic plasma exchange in treatment of patients with peritoneal form of endometriosis, infertility and point mutations in the gene NAT2.

The study included 140 patients with infertility, peritoneal form of endometriosis and point mutations in the gene NAT2. All patients are performed laparoscopy, coagulation foci of endometriosis. In the following 93 (66.4 \%) patients were treated with a the course of therapeutic plasmapheresis using the apparatus «PCS-2» with the removal of 20-25\% the volume of circulating plasma with replacement plasma of crystalloid and colloid solutions. Before treatment were shown the signs of endotoxemia, activation of oxidative stress. After treatment with the use of plasmapheresis was revealed the significant reduction of endogenous intoxication parameters and oxidative stress. Also is noted the increase in the pregnancy rate, both independently and in IVF programs, especially during the first 3 months after treatment. The findings suggest that the efficiency of the proposed comprehensive treatment techniques (laparoscopy and subsequent course of therapeutic plasmapheresis) of patients with peritoneal endometriosis and infertility and with point mutations in the gene NAT2. The use of plasmapheresis is pathogenetically justified in patients of the studied group.

Keywords: infertility, peritoneal endometriosis, point mutations in the gene $N A T 2$, endotoxicosis, oxidative
\end{abstract} stress, therapeutic plasmapheresis, pregnancy.

\section{Introduction}

Infertility is an important medical and social problem. One of the most frequent causes of reproductive function disorder (30-40\%) is endometriosis. Half of the patients with endometriosis are identified to have point mutation in NAT2 gene. NAT2 gene product arylamine-N-acetyltransferase- 2 is known to play an important role in the acetylation of aromatic and heterocyclic amines. That is why the disorder of its function, caused by encoding gene polymorphism, leads to accumulation of endotoxins, which, in its turn, strengthens process of free-radical oxidation in a cell. The importance of oxidative stress in case of endometriosis also has been proved on the basis of studying of 
specific markers that comes with endotoxicosis, activation of lipid peroxidation, impaired microcirculation. These factors involve the usage of gemapheresis methods which have detoxification, the blood rheology corrective and immune corrective effects. Within recent years the methods of gemapheresis (or efferent methods) have been used in therapy of more than 200 different diseases [1-9], including obstetrics and gynecology. Thus, the efficiency of one of the gemapheresis method - plasmapheresis in complex therapy of placental insufficiency, after myomectomy and metrectomy, during climacteric syndrome, chronic pelvic inflammatory diseases and during preparation for assisted reproductive technology (ART) programs is proved [10-15]. The researches recommend including plasmapheresis to the complex of rehabilitation action after laparoscopic corrective-plastic operation in tubal and peritoneal infertility [16].

Plasmapheresis is used in assisted reproductive technology programs for women with tubal and peritoneal infertility to improve the blood rheological properties, microcirculation, to reduce the active influence of steroid hormones on the blood clotting in multifollicular ovarian stimulation process, to increase the stability of vascular endothelial permeability, to reduce endotoxemia level, to remove immune complexes, antiphospholipid antibodies and antibodies to chorionic gonadotropin from blood system, and for treatment and prevention of acute herpetic and cytomegalovirus infection, reduction of the pill burden on the organism and prevention of ovarian hyperstimulation syndrome.

However, up to the present moment, the issue of the pathogenetically substantiated use of plasmapheresis in treatment of patients with infertility and peritoneal form of endometriosis and point mutations in the gene NAT2 is not yet fully studied. NAT2 gene product arylamine-N-acetyltransferase- 2 is known to play an important role in the acetylation of aromatic and heterocyclic amines. That is why the disorder of its function, caused by encoding gene polymorphism, leads to accumulation of endotoxins, which, in its turn, strengthens process of free-radical oxidation in a cell [17]. The importance of oxidative stress in case of endometriosis also has been proved on the basis of studying the specific markers [18].

Taking into account that the detoxifying effect of plasmapheresis is pronounced not only because of mechanical removal of bacteria and their toxins, inflammatory mediators, metabolic products, components of destroyed and necrotic changed cells, but also because of the stimulation of organs and body systems, responsible for binding, inactivation and elimination of endo- and exotoxins, as well as for reducing free radical reactions of lipid peroxidation, it can be assumed that its usage will have a positive impact on the entire detoxification systems of the body, as well as on antioxidant protection, and, therefore, will improve the results of patients with infertility and peritoneal endometriosis treatment.

The purpose of this study was to evaluate the efficacy of therapeutic plasma exchange in treatment of patients with peritoneal form of endometriosis, infertility and point mutations in the gene NAT2.

\section{Materials and methods}

The study included 140 patients with infertility, peritoneal form of endometriosis, verified by the laparoscopy, and point mutations in the gene NAT2. All patients were performed coagulation foci of endometriosis during laparoscopy, salpingoovariolisis, fimbrioplasty (on therapeutic grounds). Then all patients were divided into 2 groups: the main group included 93 (66.4\%) women, who underwent a course of plasmapheresis (2-nd stage of complex treatment) in the next cycle after laparoscopy; the comparison group included 47 (33.6\%) patients who did not experience efferent methods of treatment. Considering the current recommendations of the European Society of Human Reproduction on the ineffectiveness of hormone replacement therapy and biologically active dietary supplements with regard to increasing fertility after surgery for endometriosis, it was decided not to prescribe any drugs. The course of therapeutic plasmapheresis (PA) for patients of the main group was held in the first phase of the menstrual cycle starting on $5^{\text {th }}$ or $6^{\text {th }}$ day and included 3 sessions of PA with an interval of 2-4 days. The procedure was carried out in the PCS2 device made by «Haemonetics» (USA). The assembly of line system was carried out under aseptic conditions, immediately before the procedure. SDA-A solution (acidic dextrose) supplied automatically in a ratio of 1/12 to the blood was used as anticoagulant. Before starting the proce- 
dure the patient was intravenously administered with heparin in an amount of 25 units for $\mathrm{kg} / \mathrm{body}$ weight. The therapeutic plasmapheresis was carried out with the blood flow to the device at speed of 25-40 $\mathrm{ml}$ per minute, depending on the catheter capacity and the vein ability. The spin speed of PCS2 centrifuge is $7500 \mathrm{rpm}$, plasma was removed at speed of 15-30 ml per min depending on speed of blood flow supply.

Simultaneously with the blood sampling and removal of plasma, it was produced the plasma replacement by crystalloid (saline $0.9 \%$ ) and colloidal (hydroxyethylated starch solutions of $6 \%$ or $10 \%$ with the molecular weight of $130 / 04$ or $200 / 04$ ) solutions at a ratio of $1: 1.5$ by volume of exfusion in the device automatic mode. In case of low albumin (less than $60 \mathrm{~g} / \mathrm{l}$ ) $10 \%$ albumin solution $(100 \mathrm{ml})$ was included in the plasma replacement procedure.

To calculate the volumes of circulating plasma and blood and quantity of plasma to remove, mathematical calculation program, based on certain anthropometric patient data and some physiological constants, was used. The circulating blood volume (CBV) was counted considering body weight, height, constitutional type based on Moore method.

$$
\mathrm{CBV}=\mathrm{M} \times \mathrm{Bq}
$$

where $\mathrm{M}$ is body weight in $\mathrm{kg}$; $\mathrm{Bq}$ is the blood quantity in $\mathrm{ml}$ per $\mathrm{kg}$ of body weight (depends on body build of a woman and is from 55 to $70 \mathrm{ml} / \mathrm{kg}$ ).

Then the hematocrit, that is triple hemoglobin level, was calculated (h \%).

$$
\mathrm{Ht}=\mathrm{Hn} \times 3 \text {, }
$$

where $\mathrm{Ht}$ is hematocrit in \%; Hn is hemoglobin contents in $\mathrm{h} \%$.

Then on the base of calculated CBV and hematocrit, CPV (circulating plasma volume) was counted:

$$
\mathrm{CPV}=\mathrm{CBV} \times(100 \%-\mathrm{Ht}) .
$$

Using estimated CPV the planning percentage of plasma to remove $(\mathrm{P})$ was calculated, adding to it $5 \%$ for additionally administrated anticoagulant solution into the affluent line, the most part of which is removed with plasma, and got the planning removing plasma quantity (RPQ):

$$
\mathrm{RPQ}=\mathrm{CPV} \times \mathrm{P} \times(100 \%+5 \%)=\mathrm{CPV} \times \mathrm{P} \times 1.05
$$

\section{Criteria for inclusion:}

1. Patients with infertility, peritoneal form of endometriosis, verified by the laparoscopy.

2. Age: $20-39$.

3. Normal ovarian reserve (FSH indicators are less than $8 \mathrm{IU} / 1$, Anti-Mullerian Hormone is more than $2 \mathrm{uh} / \mathrm{ml}$ and quantity of antral follicles is more than 10 in each ovary on the $2^{\text {nd }}-3^{\text {rd }}$ day of the cycle).

4. Presence of 3 or more point mutations in the gene NAT2.

\section{Criteria for exclusion:}

1. Patients with uterine myoma, benign ovarian tumors, hydrosalpinx, malformations of female genitalia.

2. Presence of a somatic pathology associated with the presence of point mutations in the gene NAT2 (psoriasis, neurodegenerative diseases, lung and bladder disease).

3. Patients with endocrine factor of infertility.

\section{Methods:}

1. General clinical examination

Making anamnesis the special attention was paid to menstrual and reproductive functions of patients, outcome of previous pregnancies and its complications. There were estimated frequency 
of infectious diseases in childhood, the nature of inflammation, there were got data of accompanying extragenital pathology and experienced surgeries, trauma, hereditary diseases.

\section{Genetic study}

Presence of NAT2 gene polymorphism was studied at the laboratory on the base of N. F. Gamaleya Research Institute of Epidemiology and Microbiology of Ministry of Healthcare and Social Development of the Russian Federation. All patients gave informed consent for the use of the blood for the research.

The material for this study was DNA samples separated from peripheral blood leukocytes of the patients. As a preservative one the $1 \mathrm{ml}$ of $0.5 \mathrm{M}$ EDTA pH 8.0 was used.

3. Quantitative assessment of the level of endogenous intoxication (endotoxic index (EI), the molecules of average weight (AWM)) and quantitative assessment of the level of oxidative stress (malonaldehyde (MA), superoxide dismutase (SOD), total antioxidant activity (TAA)) before and after plasmapheresis.

\section{Statistical data manipulation}

To analyze the results statistical computer programs SPSS (version 10.0.7) and Statistica (Version 6.0) for Windows were used. Differences between groups were considered to be reliable at $\mathrm{p}<0.05$.

\section{Results of research}

Results of the clinical-anamnestic and genetic characteristics of patients with infertility, peritoneal endometriosis and point mutations in the gene NAT2 have been already represented [19]. The findings draw attention to the high frequency of the respiratory and genitourinary system chronic diseases, infectious, autoimmune and allergic skin disorders; burdened oncologic and allergological anamnesis of this patients group. During the results of clinical-anamnestic study estimation it was revealed some hemoglobin decrease rates among almost all patients: its average index was $110 \pm 3 \mathrm{~g} / \mathrm{l}$ $(\mathrm{N}=120-140 \mathrm{~g} / \mathrm{l})$. The total number of leukocytes of $93 \%$ of these patients came close to the upper limit of normal rate: average $8.4 \pm 0.6 \times 10^{9} \backslash 1\left(\mathrm{~N}=4.0-9.0 \times 10^{91}\right)$, and leukogram showed that $78 \%$ of patients have imperceptible shift to the left (stabed - 7.7 $\pm 0.6 \%$, segmented $-45.2 \pm 0.3 \%$ ). This can be associated with impaired metabolism of xenobiotics caused by the point mutations in the NAT2 gene and endogenous intoxication [20].

According to the results of research, infertility treatment of the patients with peritoneal endometriosis and point mutations in the gene NAT2 is less efficient than that of patients who do not have mutations [21]. It was found out that the group of patients with infertility and peritoneal endometriosis was non-uniform in detoxification system condition and pro- antioxidant balance at the system level. Detected changes are associated with the presence or absence of point mutations in the gene NAT2: their presence is marked by increase of the endogenous intoxication level and prooxidant shift. This cohort of patients can be referred to the group of poor prognosis in relation to the frequency of intrauterine pregnancy occurrence after treatment [22].

In order to estimate the influence of efferent methods treatment on the endogenous intoxication level and oxidative stress indexes, there were tested endotoxin index (EI), the index of molecules of average weight (AWM) and quantitative assessment of malondialdehyde level (MA), superoxide dismutase (SOD), total antioxidant activity (TAA)) of patients with infertility, peritoneal endometriosis and point mutations in the gene NAT2 before and after plasmapheresis (PA).

The changes of endogenic toxicosis and oxidative stress indexes before and after plasmapheresis of patients with peritoneal form of endometriosis, infertility and point mutations in the gene NAT2 are represented in Table 1.

After plasmapheresis procedure there were noticed the reliable decrease of molecules of average weight concentration $(A W M)(p<0.05)$. Analysis of endotoxin index showed the increase of the patients' EI during complex treatment with usage of plasmapheresis $(\mathrm{p}<0.05)$.

The contrastive analysis of malondialdehyde, superoxide dismutase and total antioxidant activity concentration in the patients' blood was used to estimate the oxidative stress indexes. The results represented in the table show that in the main group of patients, who experienced plasmapheresis procedure, there were registered a significant decrease of MA concentration (from 
$4.7 \pm 0.39$ to $2.5 \pm 0.29 \mathrm{mcMol} / \mathrm{l})(\mathrm{p}<0.05)$. Superoxide dismutase and total antioxidant activity levels increased up to 23.4 and $14.8 \%$ respectively $(\mathrm{p}<0.05)$

The further examination have been carried out for 12 months to estimate the remote results of complex treatment of infertility of patients with peritoneal form of endometriosis and point mutations in the gene NAT2. The data are represented in Table 2.

Table 1

Changes of endogenic toxicosis and oxidative stress indexes before and after plasmapheresis of patients with peritoneal form of endometriosis, infertility and point mutations in the gene $N A T 2$

Index

\section{Main group $(\mathbf{n}=93)$}

Before plasmapheresis

AWM 254nm, c. u.

AWM 280nm, c. u.

EI $254 \mathrm{~nm}$

EI $280 \mathrm{~nm}$

Malondialdehyde (mcMol/1)

Superoxide dismutase (Units/gHb)

Total antioxidant status (mMol/1)

$$
\begin{aligned}
& 0.27 \pm 0.04 \\
& 0.32 \pm 0.04 \\
& 3.57 \pm 0.99 \\
& 3.18 \pm 0.97
\end{aligned}
$$$$
4.7 \pm 0.39
$$$$
1210 \pm 63.05
$$$$
1.43 \pm 0.23
$$

After plasmapheresis

$$
\begin{gathered}
0.21 \pm 0.03 * \\
0.26 \pm 0.02 * \\
4.9 \pm 0.76^{*} \\
4.1 \pm 0.49 * \\
2.5 \pm 0.29 * \\
1711 \pm 68.12 * \\
1.91 \pm 0.19 *
\end{gathered}
$$

\begin{tabular}{|c|c|c|c|c|c|c|}
\hline \multirow[b]{3}{*}{ Index } & \multicolumn{6}{|c|}{ Research group $(n=140)$} \\
\hline & \multicolumn{2}{|c|}{ Less than 3 months } & \multicolumn{2}{|c|}{$3-6$ months } & \multicolumn{2}{|c|}{ 6-12 months } \\
\hline & $\begin{array}{l}\text { Main group } \\
\quad(n=93)\end{array}$ & $\begin{array}{c}\text { Comparison } \\
\text { group } \\
(n=47)\end{array}$ & $\begin{array}{l}\text { Main group } \\
\quad(n=93)\end{array}$ & $\begin{array}{c}\text { Comparison } \\
\text { group } \\
(n=47)\end{array}$ & $\begin{array}{l}\text { Main group } \\
\quad(n=93)\end{array}$ & $\begin{array}{c}\text { Comparison } \\
\text { group } \\
(n=47)\end{array}$ \\
\hline $\begin{array}{l}\text { Independent } \\
\text { pregnancy }\end{array}$ & $\begin{array}{c}11 \\
(11.8 \%)\end{array}$ & $\begin{array}{c}4^{*} \\
(6.4 \%)\end{array}$ & $\begin{array}{c}6 \\
(6.5 \%)\end{array}$ & $\begin{array}{c}2 \\
(4.3 \%)\end{array}$ & $\begin{array}{c}6 \\
(6.5 \%)\end{array}$ & 0 \\
\hline $\begin{array}{l}\text { Pregnancy after } \\
\text { IVF programs }\end{array}$ & $\begin{array}{c}15 \\
(16.1 \%)\end{array}$ & $\begin{array}{c}5^{*} \\
(8.5 \%)\end{array}$ & $\begin{array}{c}8 \\
(8.6 \%)\end{array}$ & $\begin{array}{c}1^{*} \\
(2.1 \%)\end{array}$ & $\begin{array}{c}3 \\
(3.2 \%)\end{array}$ & $\begin{array}{c}1 \\
(2.1 \%)\end{array}$ \\
\hline $\begin{array}{l}\text { Total of progress- } \\
\text { ing intra-uterine } \\
\text { pregnancy }\end{array}$ & $\begin{array}{c}26 \\
(27.9 \%)\end{array}$ & $\begin{array}{c}9 * \\
(19.1 \%)\end{array}$ & $\begin{array}{c}14 \\
(15.05 \%)\end{array}$ & $\begin{array}{c}3^{*} \\
(6.4 \%)\end{array}$ & $\begin{array}{c}9 \\
(9.7 \%)\end{array}$ & $\begin{array}{c}1^{*} \\
(2.1 \%)\end{array}$ \\
\hline Missed abortion & $\begin{array}{c}2 \\
(2.1 \%)\end{array}$ & $\begin{array}{c}4^{*} \\
(8.5 \%)\end{array}$ & $\begin{array}{c}2 \\
(2.1 \%)\end{array}$ & 0 & $\begin{array}{c}1 \\
(1.1 \%)\end{array}$ & $\begin{array}{c}1^{*} \\
(2.1 \%)\end{array}$ \\
\hline Ectopic pregnancy & $\begin{array}{c}2 \\
(2.1 \%)\end{array}$ & $\begin{array}{c}1 \\
(2.1 \%)\end{array}$ & 0 & $\begin{array}{c}1 \\
(2.1 \%)\end{array}$ & $\begin{array}{c}1 \\
(1.1 \%)\end{array}$ & 0 \\
\hline
\end{tabular}

Note: $*$-reliable difference in comparison with indexes before the therapeutic plasmapheresis procedure $(p<0.05)$

Table 2

Remote results of complex treatment of patients with peritoneal form of endometriosis, infertility and point mutations in the gene $N A T 2$. In (\%)

Note: * reliable difference in comparison with the main group $(p<0.05)$ 
Analysis of obtained results showed that the highest frequency of pregnancies in both groups $(27.9 \%$ - in mail group and $19.1 \%$ - in comparison group) was observed during the first 3 months after treatment and it significantly decreased after 6 months of examination that is in accordance with the literature data [23]. However, in the group of patients who did not get complex treatment with usage of efferent methods, the frequency of independent pregnancies as well as occurrence of pregnancies after IVM programs was reliably lower (by 6.5 and 1.5 times respectively) during 6-12 months, than that of the main group. Calls attention to itself the fact, that the quantity of missed abortions during the first three months among the patients, who did not experience therapeutic plasmapheresis, was by 4 times higher than that of the main group $(\mathrm{p}<0.05)$ and reached $8.5 \%$.

In accordance with the literature data one of the reasons of missed abortion during the first trimester is trophoblast extensive injuries, caused by oxidative stress and disorder of pro- antioxidant systems [2]. It should be said that during the last years therapeutic plasmapheresis has been widely used in habitual non-carrying of pregnancy clinic as pregravid preparation and as a therapeutic factor during gestation $[4,21,24]$.

The quantity of patients with ectopic pregnancy did not differ significantly in studied groups.

Data analysis revealed the increase of pregnancy frequency by 2 times during 3-6 months and by 4 times during 6-12 months in the main group in comparison with patients, who did not get complex treatment. However, the efficiency of IVM programs in the main group of patients significantly decreased in 6 months after treatment from 8.6 to $3.2 \%$ that can be caused by shortterm effect of complex treatment with usage of therapeutic plasmapheresis and following recurrent changes of oxidative stress condition.

\section{Discussion}

In the end of the 90-s (XX century) it was revealed that genetically predetermined detoxification system failure can become a risk factor for the endometriosis development. The researchers proved that gene of glutathione S-transferase M1 (GST), associated with the second phase of detoxification, plays a significant role in the pathogenesis of this disease [9]. More modern studies, included experiments on rhesus macaques, proved the importance of arylamine N-acetyltransferase gene (NAT-2) polymorphism in endometriosis development [25].

It is proved that allelic variants of NAT2 gene are characterized by different activity of the enzyme $\mathrm{N}$-acetyltransferase. Depending on this, the respective carriers of allelic variants are divided into «fast», «intermediate» and «slow» acetylators [9]. The studied point mutations lead to the formation of "slow acetylation phenotype», which, according to literature data, help to reduce levels of the enzyme N-acetyltransferase, slowing the conversion of acetyl-CoA to acetoacetyl-CoA [26]. Such changes lead to xenobiotic metabolism disorder that increases endogenous intoxication level.

In addition, nowadays researchers study oxidative stress markers in follicular fluid and blood serum of patients with infertility and endometriosis; these researches are associated with the search for mechanisms that lead to a decrease in fertility in natural conception, as well as in conception when assisted reproductive technologies are used, including cases of ovicells' poor quality. The decrease of antioxidant activity was shown among the patients with endometriosis and infertility that affects both folliculogenesis and the quality of oocytes and embryos [27]. Changes in multi-component antioxidant systems function and in regulation of a certain level of lipid peroxidation cause the disorder in the normal functioning of cells, including endometrial ones, that can be a precipitating factor in the progression and dissemination of endometriosis [28-30].

It is proved that the particularities of NAT2 gene polymorphism are associated with the efficiency of the treatment of patients with infertility and peritoneal endometriosis and influence on the certain results. It is revealed that the frequency of $N A T 2$ gene point polymorphism presence (c. $341 \mathrm{~T}>\mathrm{C}$, c. $481 \mathrm{C}>\mathrm{T}$, c. $590 \mathrm{G}>\mathrm{A}$ and c. $803 \mathrm{~A}>\mathrm{G}$ ) is by 3 times lower among patients with peritoneal endometriosis who got pregnant as a result of treatment, than that of those who did not get pregnant. Patients, who do not have point mutations in the gene NAT2 can be referred to the group of good prognosis [31]. 


\section{Conclusions}

Thus, the results of the studies showed the effectiveness of plasmapheresis as a method for stabilizing the oxidative status of the system and its positive role, from clinical view, for patients with infertility and peritoneal endometriosis. After the complex treatment in this group of patients it was exposed significant increase in the number of intrauterine pregnancies occurrence (both independent and in the course of assisted reproduction programs), as well as decrease of missed abortion number.

By all appearances, this effect is relatively short-termed and allows create some "reproductive window" of fertility improvement in the group of women with point mutations in NAT2 gene and impaired detoxification system (a group of poor prognosis in relation to the uterine pregnancy occurrence), which explains the best results during 3 months after treatment.

The developed method of the differentiated approach to care of patients with infertility and peritoneal endometriosis considering particularities of NAT2 gene polymorphism allows improving significantly remote results of treatment (uterine pregnancy occurrence and its prolongation).

\section{References}

[1] Voinov, V. A. (2011). Autoimmune Diseases and Efferent Therapy. Efferent and Physical-chemical Medicine, 4, 8-13.

[2] Zolotukhin, P. V. (2010). Oxidative stress and pregnancy. Valeology, 2, 16-21.

[3] Mlinnik, R. A., Tezyaeva, S. A., Sidorov, M. A. (2011). Experience in Using a Set of Current Efferent Methods in the Treatment of Patients with Infectious Pancreonecrosis. General Reanimatology, 7 (1), 72. doi: 10.15360/1813-9779-2011-1-72

[4] Parshin, A. V., Salov, I. A., Glukhova, T. N. (2012). Usage of discrete plasmapheresis in the complex therapy of threatened abortion herpetic etiology. Mother and Child. Rostov-on-Don, 81-82.

[5] List of Diseases, the Standard of Medical Care of Which Includes Plasmapheresis (2011). Efferent and Physical-chemical Medicine, 3, 70-76.

[6] Solovyova, I. N., Ragimov, A. A. (2011). Plasmapheresis in Intensive Care and Emergency Medicine. Efferent and Physical-chemical Medicine, 1, 43-49.

[7] Cortese, I., Cornblath, D. R. (2013). Therapeutic plasma exchange in neurology: 2012. Journal of Clinical Apheresis, 28 (1), 16-19. doi: 10.1002/jca.21266

[8] Voinov, V. A. (2013). Strategy of efferent therapy in sepsis. Vestn khir im I. I. Grek, 172 (2), $74-77$.

[9] Baranova, H. (1999). Possible involvement of arylamine N-acetyltransferase 2, glutathione S-transferases M1 and T1 genes in the development of endometriosis. Molecular Human Reproduction, 5 (7), 636-641. doi: 10.1093/molehr/5.7.636

[10] Buranova, F. B., Fedorova, T. A. (2012). Plasmapheresis and Medical Ozone in Treatment of Pregnant Women After the Procedure of In Vitro Fertilization with Placental Insufficiency. Rossiyskiy Vestnik Akushera-Ginekologa, 12 (1), 43-47.

[11] Nikitina, E. V., Klimovich, O. V., Gulyaeva, L. S., Agabekov, K. F., Potashkina, I. N., Moroz, N. V. (2009). Plasmapheresis and Autoserotherapy in the Treatment and Prevention of Inflammatory Diseases of Uterine Appendages. Reproductive health in Belarus, 2, 78-80.

[12] Pyregov, A. V., Lidin, A. V., Muhamedzhanova, Yu. R., Serov, V. N. (2009). Intensive Care in Severe Preeclampsia. Vestnik anesteziologii i reanimatologii, 6 (3), 37-42.

[13] Fedorova, T. A., Gasparov, A. S., Tovmasyan, V. M. (2009). Possibilities of the Usage of Plasmapheresis with Antibiotic Targeted Transport in the Treatment of Patients with Complicated Forms of Inflammatory Diseases of Uterine Appendages. Reproductive Health of Children and Adolescents, 2, 26-34.

[14] Fedorova, T. A., Ochan, A. S. (2011). Use of Plasmapheresis in the Process of Preparation of Patients with Infertility Inflammatory Genesis for the Procedure of In Vitro Fertilization and Embryo Transfer. Efferent and Physical-chemical Medicine, 1, 50-57.

[15] Foteeva, T. S. (2010). Effect of Plasmapheresis on Life Quality Characteristics in Patients with Climacteric Syndrome. Living Systems Technologies, 7 (3), 42-46.

[16] Strelnikova, E., Danilov, A., Fedorova, T., Bakuridze, E., Foteeva, T. (2009). Complex treatment of tubal peritoneal infertility after reconstructive plastic surgery. Vrach, 2, 16. 
[17] Bondarev, G. I., Martinchik, A. N. (1984). The role of nutrition in the metabolism of foreign substances. Preventive toxicology, 2 (1), 97-109.

[18] Burlev, B. A., Dubinskaya, E. D., Ilyasova, N. A., Burlev, A. V., Gasparov, A. S. (2012). Proand antiinflammatory activity of patients with peritoneal endometriosis and adhesions of the peritoneum malogotaza. Problems of reproduction, 4, 6-11.

[19] Dubinskaya, E. D., Gasparov, A. S., Fedorova, T. A., Lapteva, N. V. (2014). Importance of $\mathrm{N}$-acetyltransferase-2 gene polymorphism of patients with infertility and peritoneal endometriosis. Problems of reproduction, 1, 41-46.

[20] Dubinskaya, E. D., Gasparov, A. S., Fedorova, T. A., Lapteva, N. V., Titov, D. C. (2014). Clinical-anamnestic and genetic characteristics of patients with infertility and peritoneal endometriosis. Vrach, 1, 52-56.

[21] Gomtsyan, G. A., Chilingaryan, K. B. (2011). Plasmapheresis in the treatment of miscarriage caused by antiphospholipid syndrome. Questions of theoretical and clinical medicine, 14 (4), 14-16.

[22] Dubinskaya, E. D., Fedorova, T. A., Lapteva, N. V., Vekilyan, O. M. (2014). Oxidative stress and endogenous intoxication of patients with infertility and peritoneal endometriosis based on NAT2 gene polymorphism. Problems of reproduction, 4, 39-44.

[23] Lee, H. J., Lee, J. E., Ku, S.-Y., Kim, S. H., Kim, J. G., Moon, S. Y., Choi, Y. M. (2013). Natural conception rate following laparoscopic surgery in infertile women with endometriosis. Clinical and Experimental Reproductive Medicine, 40 (1), 29. doi: 10.5653/cerm.2013.40.1.29

[24] Kirsanova, T. V., Tetruashvili, N. K., Dyakonova, A. A., Kozlovskaya, N. L., Kan, N. E., Fedorova, T. A. et. al (2012). Catastrophic antiphospholipid syndrome in pregnant women with systemic lupus erythematosus. Obstetrics and gynecology, 5, 97-102.

[25] Fakis, G., Boukouvala, S., Kawamura, A., Kennedy, S. (2007). Description of a novel polymorphic gene encoding for arylamine $\mathrm{N}$-acetyltransferase in the rhesus macaque (Macaca mulatta), a model animal for endometriosis. Pharmacogenetics and Genomics, 17 (3), 181-188. doi: 10.1097/fpc.0b013e328011e3ad

[26] Shevchenko, O. V., Bichkov, E. N., Svistunov, A. A., Borodulin, V. B., Sarattsev, A. V., Losev, O. E., Kiselev, A. R., Posnenkova, O. M. (2012). Influence of NAT2 gene polymorphisms on the metabolism of cholesterol of patients with hypertension. Fundamental research, 7, 219-223.

[27] Prieto, L., Quesada, J. F., Cambero, O., Pacheco, A., Pellicer, A., Codoceo, R., Garcia-Velasco, J. A. (2012). Analysis of follicular fluid and serum markers of oxidative stress in women with infertility related to endometriosis. Fertility and Sterility, 98 (1), 126-130. doi: 10.1016/j.fertnstert.2012.03.052

[28] Wong, E. W. P., Cheng, C. Y. (2011). Impacts of environmental toxicants on male reproductive dysfunction. Trends in Pharmacological Sciences, 32 (5), 290-299. doi: 10.1016/j.tips.2011.01.001

[29] Gregoraszczuk, E. L., Ptak, A. (2013). Endocrine-Disrupting Chemicals: Some Actions of POPs on Female Reproduction. International Journal of Endocrinology, 2013, 1-9. doi: 10.1155/2013/828532

[30] Rebourcet, D., Odet, F., Vérot, A., Combe, E., Meugnier, E., Pesenti, S. et. al (2010). The effects of an in utero exposure to 2,3,7,8-tetrachloro-dibenzo- $\mathrm{p}$-dioxin on male reproductive function: identification of Ccl5 as a potential marker. International Journal of Andrology, 33 (2), 413-424. doi: 10.1111/j.1365-2605.2009.01020.x

[31] Dubinskaya, E. D., Gasparov, A. S., Fedorova, T. A., Lapteva, N. V. (2014). N-acetyltransferase 2 (nat2) gene polymorphisms and the effectiveness of infertility treatment in patients with peritoneal endometriosis. International Journal of Biomedicine, 4 (1), 26-31. 